\title{
Health-related quality of life among older adults who experienced the Pohang earthquake in South Korea: A cross-sectional survey
}

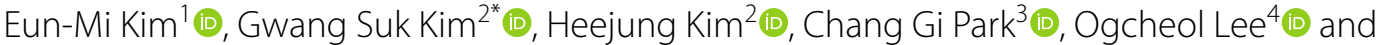 \\ Betty Pfefferbaum ${ }^{5}$ (1)
}

\begin{abstract}
Background: Earthquakes are global natural disasters and can cause loss of property, livelihood and affect human health. A 5.4 magnitude earthquake, the Pohang earthquake, occurred in South Korea in 2017. In this study, based on a health-related quality of life (HRQOL) conceptual model, we examined the HRQOL and its associated factors among older adults who had experienced the earthquake.
\end{abstract}

Methods: A cross-sectional study was conducted with a quota sample of 312 older adults living in eight villages of a district that was the most damaged area during the Pohang earthquake. Data were collected from January 15-March 19, 2019, via face-to-face interviews using structured questionnaires. Structural equation modeling was performed to explore the associations among depression, posttraumatic stress symptoms, community resilience, social support, disaster preparedness, and HRQOL.

Results: The mean age of the participants was $77.93 \pm 6.11$ years. HRQOL scores were $49.85 \pm 18.07$ (physical health), $50.16 \pm 18.75$ (psychological health), $61.93 \pm 19.20$ (social relations), and $49.53 \pm 16.37$ (environment). The structural equation modeling analysis showed a good fit. Depression had direct $(\beta=-2.21 ; p<0.001)$, indirect $(\beta=-0.23$; $p<0.001)$, and total effects on $\operatorname{HRQOL}(\beta=-2.44 ; p<0.001)$. Community resilience $(\beta=6.05 ; p=0.001)$ and social support $(\beta=0.12, p=0.001)$ had direct and total effects on HRQOL. Disaster preparedness had indirect $(\beta=0.40$; $p=0.001)$ and total $(\beta=0.69, p=0.031)$ effects on HRQOL. In contrast, posttraumatic stress symptoms did not have significant effects on HRQOL.

Conclusions: Our findings indicated that lower depression, higher community resilience, social support, and disaster preparedness were associated with increased HRQOL. Thus, it is helpful to decrease depression and strengthen community resilience, social support, and disaster preparedness to promote HRQOL among older adults who have experienced earthquakes. These results can inform the development of HRQOL in socio-psychological improvement programs for older adults in community health centers and disaster-relief psychological support centers.

Keywords: Older adults, Quality of life, Depression, Social support, Community integration, Earthquakes, Disasters

*Correspondence: gskim@yuhs.ac

2 Present Address: Mo-Im Kim Nursing Research Institute, College of Nursing, Yonsei University, Seoul, Republic of Korea

Full list of author information is available at the end of the article

\section{Background}

Worldwide, in 2019, 396 natural disasters causing 11,755 deaths, injuring 95 million people, and resulting in \$103 billion U.S. in economic losses were recorded by the Emergency Events Database, maintained by Center for Research on the Epidemiology of Disasters [1]. Asia was original author(s) and the source, provide a link to the Creative Commons licence, and indicate if changes were made. The images or other third party material in this article are included in the article's Creative Commons licence, unless indicated otherwise in a credit line to the material. If material is not included in the article's Creative Commons licence and your intended use is not permitted by statutory regulation or exceeds the permitted use, you will need to obtain permission directly from the copyright holder. To view a copy of this licence, visit http://creativecommons.org/licenses/by/4.0/. The Creative Commons Public Domain Dedication waiver (http://creativeco mmons.org/publicdomain/zero/1.0/) applies to the data made available in this article, unless otherwise stated in a credit line to the data. 
one of the most highly impacted regions and experienced a burden that accounted for $40 \%$ of disasters, $45 \%$ of deaths, and $74 \%$ of the total number of people affected [1]. On November 15, 2017, a 5.4 magnitude earthquake occurred in Pohang city, South Korea. The earthquake caused extensive damage: 544 households were damaged, 1,392 people were displaced, and, reportedly, financial losses amounted to 55,057 million Korean won (approximately USD 48 million) [2].

Earthquakes lead to undesirable changes in lifestyle and harm residents' physical and psychological health [3-5], which ultimately may lead to decreased health-related quality of life (HRQOL) [4, 6, 7]. Older adults are more vulnerable in disaster situations as they are prone to experience greater issues owing to less mobility, physical disability, and impaired cognitive abilities as compared to their younger counterparts $[8,9]$. A previous study reported that the HRQOL scores of older adults who experienced earthquakes are lower than those of other adults who have not experienced earthquakes [10]. A systematic review reported that older adults are more likely to have a higher mortality rate during earthquakes than other demographic groups [6]. Therefore, in the event of a disaster, careful attention should be paid to older adults.

Studies such as by the Bam [8], Chi-Chi [11], L'Aquila [10, 12], Niigata-chuetsu [13], and Sichuan [4] earthquakes identified older adults' $\mathrm{HRQOL}$ in various regions and post-earthquakes. These studies also investigated various factors associated with older adults' HRQOL, which included older age $[4,8,10]$, sex $[8,10,13]$, education level $[4,10]$, physical disease $[4,13]$, injury $[8]$, difficulty with activities of daily living (ADL), depression [9], post-disaster stress, living alone, poor living conditions [8], and loss of family members [4].

Social and environmental factors are also associated with HRQOL, which indicates the importance of community efforts toward recovery and social support. Social isolation [12], disruption of social networks [12], and reduced social support [9] are associated with decreased HRQOL. Furthermore, older adults have difficulties in acquiring disaster information during earthquakes and maintaining social networks [12]. In South Korea, older adults often live in an area for a long time and have close relationships with their neighbors. In the event of a disaster, if social support decreases and social isolation occurs, older adults may become more vulnerable $[9,11]$. Additionally, if many patients are admitted in hospitals, older people may have difficulties accessing the medical services they need [8].

After the Pohang earthquake, social interest in disaster management and community resilience-a comprehensive concept related to disaster risk reduction activities and community effort for recovery-increased in South
Korea $[2,14,15]$. In disaster situations, essential human needs like food, clothing, and shelter are threatened; thus, the government's disaster management organization is important, including disaster policy, resource distribution, and relief for victims [16]. Satisfaction with economic and social rights is positively associated with HRQOL $[16,17]$. Community efforts to recover from a disaster, including rescue policies [18], economic and social rights [16], community resilience [19, 20], and financial support [20] are also associated with HRQOL. Disaster preparedness, which includes disaster risk reduction activities and health-protective behaviors during life-threatening disasters is also positively associated with HRQOL [19]. Studies have also emphasized the importance of social support [12, 21].

A majority of extant studies focus on victims' basic rights and HRQOL-related policies. Few studies have identified the association between social environmental factors such as community resilience, disaster preparedness, social support, and HRQOL after an earthquake. Community resilience and social support are expected to improve victims' HRQOL by alleviating individual psychological difficulties $[15,22]$. However, owing to the lack of empirical examination in disaster practice among vulnerable older adults, it is difficult to grasp the major effects and mediated effects of community resilience, disaster preparedness, and social support on HRQOL.

Several studies have investigated the factors associated with older adults' HRQOL in diverse overseas settings after earthquakes have occurred; however, few studies have focused on vulnerable older adults in South Korea. Additionally, researchers have identified the associations between depression, posttraumatic stress symptoms (PTSS), community resilience, disaster preparedness, and social support and HRQOL among adults [16, 18, 19]; however, the multidimensional factors, including individual and social environmental aspects among older adults, require elucidation. In areas where earthquakes have occurred, conducting surveys regarding vulnerable populations' HRQOL may provide specific insights and valuable information to improve healthcare services, disaster preparedness, psychological supporting programs during and after disasters, and disaster policies and management.

\section{Conceptual framework}

The conceptual framework of this study is based on the modified HRQOL model developed by Wilson and Cleary [23] and revised by Zubritsky et al. [24]. HRQOL includes aspects such as functional, physical, and emotional health [25]. The HRQOL model developed by Wilson and Cleary [23] describes the multidimensional domains of health and comprehensively specifies a series 
of critical concepts by using a causal pathway. Zubritsky et al. [24] revised this model by focusing on highpriority performances of older adults such as cognition and behavior. The modified HRQOL model expanded the existing conceptual framework by establishing a bidirectional causal relationship of the multidimensional domains.

\section{Aim and objectives}

The current study aimed to identify associations between HRQOL and multidimensional factors among older adults in areas where the earthquake had occurred. The specific objectives were as follows: 1) to identify the status of older adults' HRQOL; 2) to establish a hypothetical model that describes the associations among community resilience, social support, disaster preparedness, depression, PTSS, ADL, instrumental ADL (IADL), and HRQOL based on the above-mentioned theoretical model; and 3) to evaluate the suitability of the hypothetical model using structural equation modeling (SEM).

\section{Methods}

\section{Design and setting}

The current study was conducted using a cross-sectional design. It was conducted in eight villages in Heunghae district, Pohang city, South Korea-one of the areas most damaged by the earthquake.

\section{Participants}

Participants were selected by proportional quota sampling. The number of older adults were calculated proportionately based on the actual number of older adults aged 65 or older living in each of the eight villages compiled by the Heunghae district Administrative Welfare Center (June 27, 2018). The study sample comprised 500 older adults from the eight villages, who were recruited according to the proportions as follows: Namsung-ri (26.0\%), Masan-ri (19.9\%), Mangchen-ri (4.8\%), Sungnae-ri (2.8\%), Yaksung-ri (10.7\%), Oksung-ri (21.7\%), Jungsung-ri (10.5\%), and Haksung-ri (3.6\%). Participant inclusion criteria were as follows: (a) older adults aged $\geq 65$ years; (b) scoring more than 24 points on the Korean version of the Mini-Mental State Examination; and (c) able to communicate, understand, and respond to questionnaires in Korean. Older adults who had difficulty understanding and responding to the questionnaire (e.g., owing to cognitive disabilities) were excluded. A total of 332 older adults participated in this study during the data collection period. After excluding 20 insufficient responses, 312 responses from older adults were analyzed (total response rate $=62.4 \%$ ). This study used a priori sample size calculator for SEM; the minimum sample size to detect a small effect size, at a desired power of 0.80 with 17 latent variables and three observed variables, was calculated as 296 (Fig. 1) [26]. Therefore, the 312 participants in the current study met the minimum sample size requirements.

\section{Ethical considerations}

This study obtained ethical approval from the appropriate Institutional Research Board (no. Y-2018-0111). Participants were provided with explanations about the research, such as purpose, necessity, and data collection method. Participants voluntarily agreed to participate and provided written consent. In order to ensure anonymity and confidentiality, anonymized data was collected. Those who participated were provided with a transportation fee reimbursement. Questionnaires and databases were confidentially managed.

\section{Instruments \\ Health-related quality of life}

HRQOL was assessed using the abbreviated brief version of the World Health Organization (WHO) questionnaire (WHOQOL-BREF), which consists of 26 items, and is a simplified version of the 100-item World Health Organization Quality of Life scale. The WHOQOL-BREF includes physical health, psychological health, social relations, and environmental domains as well as two individual items about subjective quality of life and health conditions. We used the Korean version of the WHOQOL-BREF, which was adapted by Min and colleagues [27]. Responses were measured with a five-point Likert scale. Higher scores indicated better quality of life [28]. The scale has good reliability: Cronbach's alphas were 0.90 , and 0.89 [27] among the South Korean population. In this study, Cronbach's alpha was 0.86 .

\section{Community resilience}

Community resilience was assessed using the Communities Advancing Resilience Toolkit (CART) Assessment Survey developed by Pfefferbaum and colleagues $[29,30]$. In this study, the Korean version of CART was developed and utilized in compliance with the WHO's translation guidelines [31]. Further, it was assessed for its content validity, construct validity, and reliability. All values for validity and reliability were found to be acceptable. The CART includes 26 items with five core interrelated subdomains: (a) connection and caring, (b) resources, (c) transformative potential, (d) disaster management, and (e) information and communication. Responses were measured with a five-point Likert scale (from $1=$ "strongly disagree" to $5=$ "strongly agree"). The Cronbach's alphas were 0.87 previously [29] and 0.91 in this study. 


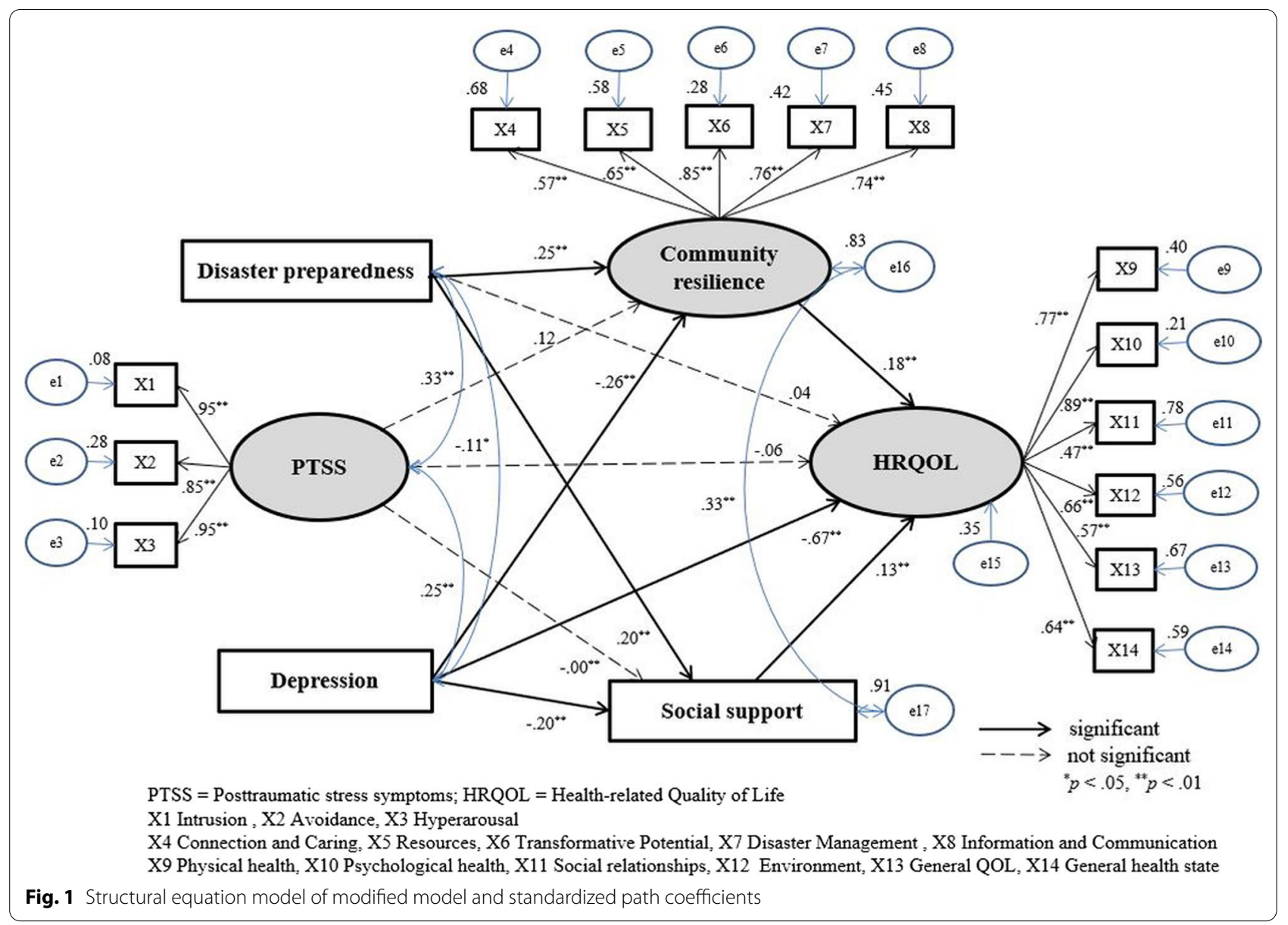

\section{Social support}

Social support was assessed using the Crisis Support Scale developed by Joseph and colleagues [32]. In this study, the Korean version was developed and utilized in compliance with WHO's translation guidelines [31]. After a disaster, the degree of social support might vary over time. The measure contains seven items, each asked on two separate occasions: within three months following the event (Time 1) and within the last three months (Time 2). In this study, to identify the overall degree of social support, the average values for Time 1 and Time 2 were calculated. Questions concerned (a) the availability of others, (b) contact with other survivors, (c) confiding in others, (d) emotional support, (e) practical support, and (f) satisfaction with support. Responses were measured with a seven-point Likert scale (from $1=$ "never" to $7=$ "always"). Higher scores indicate greater support. A total Time 1 crisis support score was obtained by summating items $1,3,5,7,9$, and 11 (reversed). Similarly, a total Time 2 crisis support score was obtained by summating items $2,4,6,8,10$, and 12 (reversed). The Cronbach's alphas were 0.80 previously [32] and 0.86 in this study.

\section{Disaster preparedness}

Disaster preparedness refers to the extent of a community's or an individual's preparedness to reduce earthquake damages, which includes disaster risk reduction activities and disaster preventive actions. We developed 13 items about disaster preparedness based on literature [15] and the National Action Guidelines for Earthquakes, developed by the South Korean government [33]. Items were validated using content validity from a panel of experts in disaster practice and reseach. Each item had two response options: "yes" or "no." The scores of each question were added: one point for "yes" and zero points for "no." Cohen's Kappa was 0.46 in this study.

\section{Depression}

Depression was assessed using the short form of the Geriatric Depression Scale-15 (GDS-15), which was developed based on the standardized GDS by Yesavage and 
colleagues [34]. Kee [35] developed the Korean version of the GDS-15 and verified its validity and reliability. The scale consists of 15 items. Each item has two response options: "yes" or "no." Total scores range from 0-15 and higher scores indicate more severe depression. Cronbach's alphas were 0.94 [34] and 0.88 [35] previously. In this study, the Kuder-Richardson Formula 20 was 0.86 . Statistically, in this case, the KR-20 is a more appropriate method than Cronbach's alpha for testing reliability, as this scale consisted of dichotomized response pattern, and the value was 0.86 , which indicates high internal consistency.

\section{Posttraumatic stress symptoms}

PTSS were assessed using the Korean version [36] of the 22-item Impact of Event Scale-Revised (IES-R) [37], which assesses posttraumatic stress disorder symptoms after a specific traumatic stressor. It is one of the most widely used measures in trauma-related research. It consists of three subscales corresponding to the three dimensions of the criteria for posttraumatic stress disorder outlined in the fourth edition of the Diagnostic and Statistical Manual of Mental Disorders [38]: intrusion (eight items), avoidance (eight items), and hyperarousal symptoms (six items). Responses were measured using a five-point Likert scale $(0=$ "not at all" to $4=$ "often"). Cronbach's alphas were 0.79 previously [37] and 0.95 in this study.

\section{Activities of daily living}

Activities of daily living were assessed with the Korean version of the ADL scale developed by Won and colleagues [39]. The scale has 17 items and includes two parts: ADL and IADL. The ADL component has seven items related to dressing, washing one's face, bathing, eating, moving, going to the bathroom, and continence. The IADL has ten items related to participants' abilities concerning grooming, housekeeping, preparing meals, laundry, transportation use, money management, telephone use, shopping, going out to nearby places, and taking one's medicine. The total score is calculated as the sum of each item using a three-point Likert scale. The ADL scores range from 7 to 21 , while the IADL scores range from 10 to 30 . Higher scores indicate better physical health. Cronbach's alphas were 0.94 previously [39], and 0.78 in this study.

\section{Socio-demographic factors}

The socio-demographic factors that we measured included age, sex, marital status, education level, religion, family cohabitation, working conditions, and monthly income.
The tools, such as, WHOQOL-BREF, GDS-15, IES-R, and ADL, were used in this study and have already been tested for reliability in the Korean population. The 312 older adults were used to evaluate reliability for each variable and to see if the results reflect whether the tools well measured the concept for study subjects in this study. The following tools were used for the first time in a Korean sample (CART, Crisis support scale, and Disaster preparedness), with the study used to confirm the reliability of the subjects in this study to provide evidence on the reliability for future research.

\section{Data collection}

Data were collected from January 15 to March 19, 2019. Surveyors visited 22 local facilities, such as centers for senior citizens, schools for senior citizens, and temporary residential shelters in eight villages in Heunghae district to collect data. Ten surveyors conducted face-to-face interviews using structured questionnaires. Prior to data collection, educational training was conducted for the ten surveyors regarding the survey purpose, inclusion/exclusion criteria, data collection methods, obtaining consent, among other things. Data were collected after obtaining permission and cooperation from 22 local facilities. Research information was posted at these local facilities to recruit participants in advance. It took each participant about 30-40 min to complete the questionnaire.

\section{Data analysis}

Data analysis was performed using IBM SPSS statistics version 23.0 (IBM Corp., Armonk, NY, USA) and Stata version 13.0 (Stata Corp., College Station, TX, USA). Descriptive statistics were calculated for socio-demographic characteristics and study variables, including percentage, frequency, mean, and standard deviation. T-tests, one-way analyses of variance, and Pearson's correlation coefficients were used to identify the differences and relationships between study variables. SEM was used to test the model fit between the hypothetical model and the collected data. Multicollinearity was checked with tolerance and variation inflation factors. The multivariate normality of the sample was identified using Doornik-Hansen test [40]. Although it is recommended that the multivariate normality assumption is met for SEM analysis, this is rare among such data. If univariate normality is satisfied, the data are considered appropriate for SEM analysis [41]. Univariate normality is not satisfied if the skewness index $>3$ and the kurtosis index $>7$. The data from the current study did not satisfy these multivariate normality assumptions. Except for ADL and IADL, the univariate normality assumptions were satisfied. The ADL and IADL were initially included in the hypothetical model as exogenous 
variables, but they were excluded in the results of the final analysis. Bootstrapping was used to verify the significance of the direct, indirect, and total effects of the hypothetical model. The evaluation of the goodness of model fit is presented in Table 3 and based on the following criteria: $\chi^{2}(\mathrm{CMIN})$, normed $\chi^{2}(\mathrm{CMIN} / \mathrm{df}) \leq 3$, standard root mean residual $(S R M R) \leq 0.05,0.06 \leq$ root mean squared of approximation (RMSEA) $\leq 0.08$, comparative fit index $(\mathrm{CFI}) \geq 0.90$, and Tucker-Lewis index $(\mathrm{TLI}) \geq 0.90$.

\section{Results}

\section{General characteristics of the participants}

Participants' general characteristics are presented in Table 1 . Of the 312 older adults, the mean age of participants was $77.93 \pm 6.11$ years: 160 participants (51.3\%) were of ages 75-84 years and 104 (33.3\%), 65-74 years. Most were women $(n=217 ; 69.6 \%), 166(53.2 \%)$ were married, 166 (53.2\%) had only an elementary school level of education, 182 (58.3\%) were older adults living with their families, and 234 (75.0\%) were unemployed.

Table 1 General characteristics of participants $(N=312)$

\begin{tabular}{|c|c|c|c|}
\hline Characteristics & Categories & $n(\%)$ & Mean $\pm S D$ \\
\hline \multirow[t]{4}{*}{ Age (year) } & & & $77.93 \pm 6.11$ \\
\hline & $65-74$ & $104(33.3)$ & \\
\hline & $75-84$ & $160(51.3)$ & \\
\hline & $\geq 85$ & $48(15.4)$ & \\
\hline \multirow[t]{2}{*}{ Sex } & Male & $95(30.4)$ & \\
\hline & Female & $217(69.6)$ & \\
\hline \multirow[t]{2}{*}{ Marriage } & Married & $166(53.2)$ & \\
\hline & Bereavement or divorce & $146(46.8)$ & \\
\hline \multirow[t]{4}{*}{ Education } & No school & $58(18.6)$ & \\
\hline & Elementary school & $166(53.2)$ & \\
\hline & Middle school & $59(18.9)$ & \\
\hline & $\geq$ High school & $29(9.3)$ & \\
\hline \multirow[t]{4}{*}{ Religion } & None & $119(38.1)$ & \\
\hline & Buddhism & $115(36.9)$ & \\
\hline & Christianity & 65 (20.8) & \\
\hline & Others & $13(4.2)$ & \\
\hline \multirow[t]{2}{*}{ Family cohabitation } & Living alone & $130(41.7)$ & \\
\hline & Living with family & $182(58.3)$ & \\
\hline \multirow[t]{3}{*}{ Working condition } & Full time & $31(9.9)$ & \\
\hline & Part time & $47(15.1)$ & \\
\hline & Without job & $234(75.0)$ & \\
\hline \multirow{3}{*}{$\begin{array}{l}\text { Monthly income } \\
(n=303 ; 10,000 \\
\text { won) }\end{array}$} & $<50$ & $160(52.8)$ & \\
\hline & $50-99$ & $94(31.0)$ & \\
\hline & $\geq 100$ & $49(16.2)$ & \\
\hline
\end{tabular}

$\mathrm{SD}=$ Standard deviation

\section{Descriptive statistics of the study variables}

The mean overall HRQOL score among older adults was $51.39 \pm 14.60$. The mean community resilience score was $3.24 \pm 0.64$ and the mean PTSS score was $1.90 \pm 0.97$. The mean depression score was $6.57 \pm 4.23$, disaster preparedness was $7.33 \pm 2.30$, and social support was $28.30 \pm 7.06$ (Table 2).

\section{Structural model of HRQOL}

The hypothetical model based on the modified HRQOL model developed by Wilson and Cleary [23] and revised by Zubritsky et al. [24] from the SEM analysis is illustrated in Fig. 1. The SEM model fit indices are presented in Table 3. The model fit of the hypothetical model was adequate: $X^{2}=292.61 \quad(p<0.001)$, normed $\chi^{2}=2.73$, SRMR $=0.05$, RMSEA $=0.07, \mathrm{CFI}=0.93$, and TLI $=0.91$. The hypothetical model was modified considering modification indices and theoretical background by connecting the error terms with the highest modification indices. In the modified model of this study, error terms with e16 and 17 were connected. The fit of the modified model was more adequate than that of the hypothetical model: $\chi^{2}=253.55(p<0.001)$, normed $\chi^{2}=2.39$, SRMR $=0.04$, RMSEA $=0.06, C F I=0.94$, and TLI $=0.93$. Therefore, the results showed that the goodness-of-fit of the modified model was acceptable.

Standardized regression coefficients $(\beta)$ for each path in the modified model, along with $p$-values, are presented in Fig. 1. Depression $(\beta=-0.67, p<0.01)$ had significant negative effects on participants' HRQOL. Community resilience $(\beta=0.18, p<0.01)$ and social support $(\beta=0.13$, $p<0.01)$ had significant positive effects on participants' HRQOL.

To identify the direct, indirect, and total effects on HRQOL, the results of effect analysis using bootstrapping are presented in Table 4. Depression had significant negative direct $(\beta=-2.21 ; p<0.001)$, indirect $(\beta=-0.23 ; p<0.001)$, and total $(\beta=-2.44 ; p<0.001)$ effects on HRQOL. Community resilience $(\beta=6.05$; $p=0.001)$ and social support $(\beta=0.12, p=0.001)$ had significant direct and total effects on HRQOL. Disaster preparedness had significant indirect $(\beta=0.40 ; p=0.001)$ and total $(\beta=0.69, p=0.031)$ effects on HRQOL. However, PTSS did not have significant effects on HRQOL.

\section{Discussion}

Disasters such as earthquakes could do extensive damage to the general health of older adults and reduce their HRQOL. To the best of our knowledge, this study was the first attempt to identify the degree of HRQOL and the paths between associated factors and HRQOL among older adults who experienced the Pohang earthquake in 
Table 2 Descriptive statistics of observed variables $(N=312)$

\begin{tabular}{|c|c|c|c|c|}
\hline Variable & Range & Mean $\pm S D$ & Min & Max \\
\hline HR-QOL & $0-100$ & $51.39 \pm 14.60$ & 11.71 & 91.87 \\
\hline 1. Physical health & $0-100$ & $49.85 \pm 18.07$ & 0.0 & 96.43 \\
\hline 2. Psychological health & $0-100$ & $50.16 \pm 18.75$ & 4.17 & 100.00 \\
\hline 3. Social relationships & $0-100$ & $61.93 \pm 19.20$ & 0 & 100.00 \\
\hline 4. Environment & $0-100$ & $49.53 \pm 16.37$ & 3.13 & 93.75 \\
\hline 5. General quality of life & $0-100$ & $53.44 \pm 20.00$ & 0 & 100.00 \\
\hline 6. General health state & $0-100$ & $43.42 \pm 26.91$ & 0 & 100.00 \\
\hline Community resilience & $1-5$ & $3.24 \pm .64$ & 1.23 & 5.00 \\
\hline 1. Connection and caring & $1-5$ & $3.69 \pm .71$ & 1.00 & 5.00 \\
\hline 2. Resources & $1-5$ & $2.75 \pm .85$ & 1.00 & 5.00 \\
\hline 3. Transformative potential & $1-5$ & $3.12 \pm .75$ & 1.13 & 5.00 \\
\hline 4. Disaster management & $1-5$ & $3.30 \pm .95$ & 1.00 & 5.00 \\
\hline 5. Information and communication & $1-5$ & $3.47 \pm .90$ & 1.00 & 5.00 \\
\hline Social support & $7-42$ & $28.30 \pm 7.06$ & 11.00 & 42.00 \\
\hline 1. Time 1 ; in the 3 months after events & $7-42$ & $29.41 \pm 7.42$ & 11.00 & 42.00 \\
\hline 2. Time 2 ; last 3 months & $7-42$ & $27.19 \pm 7.52$ & 8.00 & 42.00 \\
\hline Disaster preparedness & $0-13$ & $7.33 \pm 2.30$ & 0 & 13.00 \\
\hline Depression & $0-15$ & $6.57 \pm 4.23$ & 0 & 15.00 \\
\hline PTSS & $0-4$ & $1.90 \pm .97$ & 0 & 4.00 \\
\hline 1. Intrusion & $0-4$ & $1.95 \pm .98$ & 0 & 4.00 \\
\hline 2. Avoidance & $0-4$ & $1.85 \pm 1.00$ & 0 & 4.00 \\
\hline 3. Hyperarousal & $0-4$ & $1.92 \pm 1.12$ & 0 & 4.00 \\
\hline $\mathrm{ADL}$ & $7-21$ & $7.07 \pm .32$ & 7.00 & 9.00 \\
\hline IADL & $10-30$ & $10.38 \pm 1.21$ & 10.00 & 19.00 \\
\hline
\end{tabular}

$\mathrm{SD}=$ Standard deviation; $\mathrm{HR}-\mathrm{QOL}=$ Health-related quality of life; $\mathrm{PTSS}=$ posttraumatic stress symptoms; $\mathrm{ADL}=$ activities of daily living; $\mathrm{IADL}=\mathrm{instrumental}$ activities of daily living

Table 3 Structural equation models and model fit indices $(N=312)$

\begin{tabular}{llll}
\hline Model fit index & Acceptable criteria & Hypothetical model & Modified model \\
\hline$X^{2}($ CMIN) & Lower & 292.61 & 253.55 \\
Normed X2 (CMIN/df) & $\leq 3.0$ & 2.73 & 2.39 \\
$p$ & $>0.05$ & $<0.001$ & $<0.001$ \\
SRMR & $\leq 0.05$ & 0.05 & 0.04 \\
RMSEA & $\leq 0.05$ (good) & 0.07 & 0.06 \\
CFI & $\leq 0.08$ (acceptable) & 0.93 & 0.94 \\
TLI & $\geq 0.90$ & 0.91 & 0.93 \\
Parsimonious fit index & $\geq 0.90$ & & 2858.56 \\
AlC & & $30,016.47$ & \\
\hline
\end{tabular}

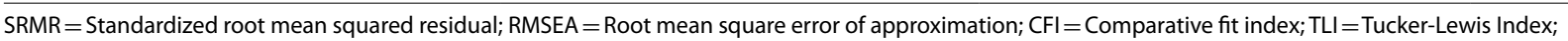
$\mathrm{AIC}=$ Akaike information criterion

South Korea. Because earthquakes are relatively rare in Korea, support systems for vulnerable populations are insufficient. Recently, advocating for the health of vulnerable older adults in areas where disasters have occurred has become a noteworthy phenomenon in South Korea.
Thus, we constructed a hypothetical model based on the HRQOL model [23, 24]. This study verified the suitability of the model and the significance of its paths and direct, indirect, and total effects of factors on HRQOL among older adults. 
Table 4 Standardized direct, indirect, and total effects of the modified model ( $N=312)$

\begin{tabular}{|c|c|c|c|c|c|c|c|}
\hline \multirow[t]{2}{*}{ Endogenous variable } & \multirow[t]{2}{*}{ Exogenous variable } & \multicolumn{2}{|c|}{ Total effect } & \multicolumn{2}{|c|}{ Direct effect } & \multicolumn{2}{|c|}{ Indirect effect } \\
\hline & & $\beta$ & $p$ & $\beta$ & $p$ & $\beta$ & $p$ \\
\hline \multirow[t]{5}{*}{ HRQOL } & $\leftarrow$ Depression & -2.44 & $<0.001$ & -2.21 & $<0.001$ & -0.23 & $<0.001$ \\
\hline & $\leftarrow$ Community resilience & 6.05 & 0.001 & 6.05 & 0.001 & - & - \\
\hline & $\leftarrow$ Social support & 0.12 & 0.008 & 0.12 & 0.008 & - & - \\
\hline & $\leftarrow$ PTSS & -0.07 & 0.403 & -0.11 & 0.193 & 0.03 & 0.164 \\
\hline & $\leftarrow$ Disaster preparedness & 0.69 & 0.031 & 0.28 & 0.359 & 0.40 & $<0.001$ \\
\hline \multirow[t]{3}{*}{ Community resilience } & $\leftarrow$ Depression & -0.02 & $<0.001$ & -0.02 & $<0.001$ & - & - \\
\hline & $\leftarrow$ Disaster preparedness & 0.04 & $<0.001$ & 0.04 & $<0.001$ & - & - \\
\hline & $\leftarrow$ PTSS & 0.00 & 0.060 & 0.00 & 0.060 & - & - \\
\hline \multirow[t]{3}{*}{ Social support } & $\leftarrow$ Depression & -0.67 & $<0.001$ & -0.67 & $<0.001$ & - & - \\
\hline & $\leftarrow$ Disaster preparedness & 1.17 & 0.002 & 1.17 & 0.002 & - & - \\
\hline & $\leftarrow$ PTSS & -0.00 & 0.954 & -0.00 & 0.954 & - & - \\
\hline
\end{tabular}

Bootstrap replications 50; $\mathrm{HRQOL}=$ Health-related Quality of Life; PTSS $=$ Posttraumatic stress symptoms

The HRQOL scores among the participating older adults were 49.88 for physical health, 49.98 for psychological health, 61.69 for social relations, and 49.52 for environment. These results were similar to the findings of Xie and colleagues [9], who used the same measuring tool for older adults (mean age $=74.4$ years) living in temporary facilities after the 8.0 magnitude Wenchuan earthquake in China (56.2 for physical health, 45.7 for psychological health, 64.2 for social relations, and 52.9 for the environment). Further, in a post-earthquake follow-up study [10], the HRQOL perceived by adults and older individuals who experienced the L'Aquila earthquake in Italy was somewhat higher than that reported in this study.

Xie and colleagues [9] assert that social attention should be paid to the HRQOL of vulnerable older adults in chaotic disaster situations because they are susceptible to lower HRQOL than younger adults. The current study was conducted based on the assumption that older adults might be more prone to chronic diseases, have limited physical abilities, have difficulty accessing disaster information, and experience a lack of appropriate health services $[8,9]$. Thus, community leaders and healthcare providers should pay careful attention and provide appropriate interventions for the subdomains of HRQOL. In turn, this could help promote the health of older adults in South Korea.

The findings from our structural equation model clarified that depression, community resilience, social support, and disaster preparedness were associated with HRQOL among earthquake-affected older adults. Further, the model fit indices of the modified model were acceptable, confirming that the proposed conceptual model was supported. Depression, community resilience, and social support had significant direct and total effects on HRQOL. Depression and disaster preparedness had significant indirect and total effects on HRQOL. In contrast, PTSS had non-significant effects on HRQOL.

Depression showed significant negative direct, indirect, and total effects on HRQOL, which is consistent with the results of previous studies on older adults [9] and adults between 18 to 65 years [7,22, 42]. Older adults with depression have difficulties adjusting to chaotic disaster situations and building social relationships with others in unfamiliar environments, such as temporary residential facilities [42]. The impact of depression might lead to reduced outdoor activities, job performance and increased use of healthcare services, which might subsequently result in lower HRQOL [42, 43]. The application of exercise programs developed for older adults who were affected by the 2011 earthquake and tsunami in Japan improved their mental health, which positively contributed to improving their HRQOL [43]. The key factors of the exercise program included being conducted by trained nurses and the promotion of exercise and social interactions. When applying the program for older adults, it may prove effective in strengthening their mental health by encouraging interest, social relationships, and physical activities [43].

Community resilience had significant positive direct and total effects on older adults' HRQOL, which coincides with studies reporting that government support and policies [16], disaster preventive policies [18], and understanding of policy issues [44] are associated with increased HRQOL. Furthermore, community resilience mediated the effects of depression and disaster preparedness on HRQOL. This might be because community resilience stems from strong positive emotional reactions that 
can help an individual overcome negative emotions such as depression in disaster situations. In this way, community resilience might have served as a buffer for negative emotions owing to reduced HRQOL [15, 22]. Additionally, it is reported that people who were involved in education or volunteer to reduce disaster risk may have a higher awareness of community resilience [15]. These findings suggest that the application of community resilience improvement programs for vulnerable older adults might be an effective way to improve HRQOL and should be implemented by people with educational or volunteering experience in disaster risk management programs. Maintaining a supportive social network of community resources and educational training programs about disasters, risk prevention, risk reduction techniques, evacuation, and survival skills are valuable practices $[15,45]$.

Social support had significant positive direct and total effects on older adults' HRQOL, which is aligned with previous studies' findings that focused on the older adult group [9, 22] and adults in general [21, 22, 42]. Additionally, social support mediated the effects of depression on HRQOL, which is also consistent with previous research [22]. When depression negatively affects HRQOL, social support may have a buffering effect $[21,46]$. As older people experience a sense of social isolation and social network disruption owing to the long-term effects of earthquakes [12], it is crucial to note that social support mitigates these negative effects on people's HRQOL, thus alleviating both physical and psychological damage and resulting in increased HRQOL [21]. Social support provides practical assistance, such as short-term emergency relief in the immediate aftermath of earthquakes, as well as long-term healthcare and social services to reduce health deterioration and relieve stress $[9,21]$. The results also revealed that social support scores decreased as time passed (from 3 months after the earthquake to about 1 year after the earthquake). These results suggest that social support may be high soon after a disaster but decreases over time. Therefore, strengthening the mid- to long-term social support system for vulnerable older adults may be an effective strategy to improve their HRQOL.

Disaster preparedness had significant positive indirect and total effects on HRQOL by mediating the effects of community resilience and social support. This suggests that disaster preparedness as part of disaster risk reduction activities in communities could indirectly result in increased HRQOL [15]. These results are consistent with a previous finding that disaster preparedness has positive associations with spiritual wellbeing, emotional well-being, and life satisfaction [19]. Moreover, disaster preparedness was associated with increased community resilience and social support, which implies that preventive measures and activities could strengthen the coping capacity of communities that are recovering from earthquake damage [15]. In light of these findings, the government and private institutions should continue to strengthen older adults' disaster preparedness.

Finally, PTSS was not significantly associated with older adults' HRQOL, which was inconsistent with previous findings [3, 42, 47-51]. The reason for this inconsistency might be that the magnitude of the Pohang earthquake was relatively small compared to those of earthquakes in previous studies, such as Van in Turkey or Sichuan in China $[3,51]$. Consequently, the degree of damage to human life and well-being would have been relatively minor. However, PTSS is an important health issue for vulnerable older adults, and social interests are necessary to consider when screening high-risk groups and providing intervention programs at the community level [4]. The current study adds to the existing knowledge that it might be an effective strategy to provide disaster-relief psychological support programs that prioritize depression more than PTSS in cases when the earthquake causes relatively minor damage.

\section{Limitations}

The findings should be understood within the context of the study limitations. First, the self-report responses from the older adults were obtained 1 year after the earthquake. Thus, it is difficult to rule out recall bias and memory deterioration. Second, this study is limited in its ability to identify the level of depression and associated factors before the earthquake. The results of the current study should be interpreted carefully. Third, the study's cross-sectional design is a weakness because it cannot explain causal inferences. Longitudinal studies can provide more precise information on causal pathways. Fourth, although participants were selected through proportional quota sampling, data collection was conducted in places that were relatively easy to access, such as senior citizen centers, senior citizen schools, and temporary housing facilities. Additionally, some people whose houses were severely damaged were living elsewhere at the time the research was conducted. Thus, it is difficult to rule out the possibility that the results might have been overestimated or underestimated. Careful attention is required in generalizing the results to the entire older population of South Korea. Despite these limitations, the findings provide valuable evidence for current disaster implementation and recovery programs at disaster-relief psychological support centers and community healthcare centers. 


\section{Conclusions}

This study verified the path between associated factors and HRQOL among older adults who experienced the Pohang earthquake in South Korea by constructing a hypothetical model based on the HRQOL model developed by Wilson and Cleary [23] and revised by Zubritsky et al. [24]. The results of the modified model of the current study showed that lower depression and higher community resilience, social support, and disaster preparedness have significant effects on increased HRQOL. New perspectives on multidimensional HRQOL factors would be needed for a more comprehensive understanding on how HRQOL can be increased after an earthquake. When providing interventions to improve HRQOL among older adults, the focus should be on reducing depression and strengthening community resilience, social support, and disaster preparedness. These findings confirm existing disaster-related knowledge and provide a foundation for further research. Furthermore, they can be used as evidence to develop HRQOL improvement programs for older adults in community health centers and disaster-relief psychological support centers.

\begin{abstract}
Abbreviations
ADL: Activities of daily living; CART: Communities Advancing Resilience Toolkit; CFI: Comparative fit index; GDS-15: Short form of the Geriatric Depression Scale-15; HRQOL: Health-related quality of life; IADL: Instrumental activities of daily living; PTSS: Posttraumatic stress symptoms; RMSEA: Root mean squared of approximation; SEM: Structural equation modeling; SRMR: Standard root mean residual; TLI: Tucker-Lewis index; WHOQOL-BREF: Abbreviated World Health Organization Quality of Life questionnaire.
\end{abstract}

\section{Acknowledgements}

The researchers thank all the respondents in this survey for their time and for sharing their experience.

\section{Authors' contributions}

EK, GK, and HK designed the research; EK collected the data; EK and CP analyzed the data; EK, GK, and HK drafted the manuscript; $C P, O L$ and BP made critical revisions to the manuscript. All authors have agreed on the final version and meet at least one of the criteria recommended by the International Committee of Medical Journal Editors (ICMJE, http://www.icmje.org/recom mendations/)]. All authors read and approved the final manuscript.

\section{Funding}

This research received no specific grant from any funding agency in the public, commercial, or not-for-profit sectors.

\section{Availability of data and materials}

All data generated or analyzed during this study are included in this manuscript.

\section{Declarations}

Ethics approval and consent to participate

The study protocol was approved by the Institutional Research Board of Yonsei University Health System (Reference No.: Y-2018-0111). Informed consent was obtained from all participants in the study.

\section{Consent for publication}

Not applicable.

\section{Competing interest}

The authors declare that they have no competing interests.

\section{Author details}

${ }^{1}$ College of Nursing, Research Institute of Nursing Science, Pusan National University, Yangsan, Gyeongsangnam-do, Republic of Korea. ${ }^{2}$ Present Address: Mo-Im Kim Nursing Research Institute, College of Nursing, Yonsei University, Seoul, Republic of Korea. ${ }^{3}$ College of Nursing, University of Illinois, Chicago, IL, USA. ${ }^{4}$ Red Cross College of Nursing, Chung-Ang University, Seoul, Republic of Korea. ${ }^{5}$ Department of Psychiatry and Behavioral Sciences, College of Medicine, University of Oklahoma Health Sciences Center, Oklahoma City, USA.

Received: 31 August 2021 Accepted: 21 February 2022

Published online: 04 March 2022

\section{References}

1. Centre for Research on the Epidemiology of Disasters. Natural disaster 2019 Brussels: CRED. 2020. https://emdat.be/sites/default/files/adsr_2019. pdf. Accessed 15 March 2021.

2. Korean Ministry of Interior and Safety. 2017 Pohang earthquake white paper: From the occurrence of the Pohang earthquake to the recovery, and the remaining tasks. Sejong: Korean Ministry of interior and Safety. Report No. 2018. 11-1741000-000123-01. http://m.korea.kr/expertWeb/ resources/files/data/document_file/2018/2017\%20\%ED\%8F\%AC\%ED\% 95\%AD\%EC\%A7\%80\%EC\%A7\%84\%20\%EB\%B0\%B1\%EC\%84\%9C(\%EB\% B0\%9C\%EA\%B0\%84\%EC\%82\%AC,\%201\%EC\%9E\%A5-3\%EC\%9E\%A5).pdf. Accessed 1 June 2019.

3. Ozdemir O, Boysan M, Guzel Ozdemir P, Yilmaz E. Relationships between posttraumatic stress disorder (PTSD), dissociation, quality of life, hopelessness, and suicidal ideation among earthquake survivors. Psychiatry Res. 2015;228(3):598-605.

4. Cao X, Chen L, Tian L, Jiang X. Psychological distress and health-related quality of life in relocated and nonrelocated older survivors after the 2008 Sichuan earthquake. Asian Nurs Res. 2015;9(4):271-7.

5. Harada N, Shigemura J, Tanichi M, Kawaida K, Takahashi S, Yasukata F. Mental health and psychological impacts from the 2011 Great East Japan Earthquake Disaster: a systematic literature review. Disaster Mil Med. 2015;1(1):1-12.

6. Doocy S, Daniels A, Packer C, Dick A, Kirsch TD. The human impact of earthquakes: a historical review of events 1980-2009 and systematic literature review. PLoS Curr. 2013:5.

7. Gigantesco A, D’Argenio P, Cofini V, Mancini C, Minardi V. Health-related quality of life in the aftermath of the L'Aquila earthquake in Italy. Disaster Med Public Health Prep. 2016;10(1):11-5.

8. Ardalana A, Mazaheria M, Vanrooyena M, Mowafia H, Nedjata S, Holakouie Naienia K, et al. Post-disaster quality of life among older survivors five years after the Bam earthquake: implications for recovery policy. Age Soc. 2011:31(2):179-96.

9. Xie X, Chen Y, Chen H, Au A, Guo H. Predictors of quality of life and depression in older people living in temporary houses 13 months after the Wenchuan earthquake in western China: a cross-sectional study. Nurs Health Sci. 2017:19(2):170-5.

10. Valenti M, Masedu F, Mazza M, Tiberti S, Di Giovanni C, Calvarese A, et al. A longitudinal study of quality of life of earthquake survivors in L'Aquila. Italy BMC Public Health. 2013;13:1143.

11. Lin MR, Huang W, Huang C, Hwang HF, Tsai LW, Chiu YN. The impact of the Chi-Chi earthquake on quality of life among older survivors in Taiwan-a before and after study. Qual Life Res. 2002;11(4):379-88.

12. Giuliani AR, Mattei A, Santilli F, Clori G, Scatigna M, Fabiani L. Well-being and perceived quality of life in elderly people displaced after the earthquake in L'Aquila Italy. J Commun Health. 2014;39(3):531-7.

13. Suzuki Y, Tsutsumi A, Fukasawa M, Honma H, Someya T, Kim Y. Prevalence of mental disorders and suicidal thoughts among community-dwelling elderly adults 3 years after the niigata-chuetsu earthquake. J Epidemiol. 2011:21(2):144-50. 
14. Pfefferbaum RL, Pfefferbaum B, Van Horn RL, Klomp RW, Norris FH, Reissman DB. The communities advancing resilience toolkit (CART): an intervention to build community resilience to disasters. J Public Health Manag Pract JPHMP. 2013;19(3):250-8.

15. Cui K, Han Z, Wang D. Resilience of an earthquake-stricken rural community in Southwest China: correlation with disaster risk reduction efforts. Int J Environ Res Public Health. 2018;15(3).

16. Liang Y. Satisfaction with economic and social rights and quality of life in a post-disaster zone in China: evidence from earthquake-prone Sichuan. Disaster Med Public Health Prep. 2015;9(2):111-8.

17. Liang Y, Lu P. Health-related quality of life and the adaptation of residents to harsh post-earthquake conditions in China. Disaster Med Public Health Prep. 2014;8(5):390-6.

18. Liang $Y$, Wang $X$. Developing a new perspective to study the health of survivors of Sichuan earthquakes in China: a study on the effect of post-earthquake rescue policies on survivors' health-related quality of life. Health Res Pol Syst. 2013;11:41.

19. Gowan ME, Kirk RC, Sloan JA. Building resiliency: a cross-sectional study examining relationships among health-related quality of life, well-being, and disaster preparedness. Health Qual Life Outcomes. 2014:12(1):1-17.

20. Poortinga W. Community resilience and health: the role of bonding, bridging, and linking aspects of social capital. Health Place. 2012;18(2):286-95.

21. Ke X, Liu C, Li N. Social support and Quality of Life: a cross-sectional study on survivors eight months after the 2008 Wenchuan earthquake. BMC Public Health. 2010;10:573.

22. Xu J, Ou L. Resilience and quality of life among Wenchuan earthquake survivors: the mediating role of social support. Public Health. 2014;128(5):430-7.

23. Wilson IB, Cleary PD. Linking clinical variables with health-related quality of life: a conceptual model of patient outcomes. JAMA. 1995;273(1):59-65.

24. Zubritsky C, Abbott KM, Hirschman KB, Bowles KH, Foust JB, Naylor MD. Health-related quality of life: expanding a conceptual framework to include older adults who receive long-term services and supports. Gerontol. 2013;53(2):205-10.

25. McHorney CA. Health status assessment methods for adults: past accomplishments and future challenges. Ann Rev Public Health. 1999;20:309-35.

26. Soper DS. A-priori sample size calculator for structural equation models [Software]; 2021. http://www.danielsoper.com/statcalc. Accessed 22 October 2021.

27. Min SM, Kim Kl, Suh SY, Kim DK. Development of Korean version of World Health Organization Quality of Life Scale (WHOQOL). J Korean Neuropsychiatr Assoc. 2000;39(1):78-88

28. The WHOQOL Group. Development of the World Health Organization WHOQOL-BREF quality of life assessment. Psychol Med. 1998:28(3):551-8.

29. Pfefferbaum RL, Neas BR, Pfefferbaum B, Norris FH, Van Horn RL. The communities advancing resilience toolkit (CART): development of a survey instrument to assess community resilience. Int J Emerg Ment Health Human Resil. 2013:15(1):15-30.

30. Pfefferbaum RL, Pfefferbaum B, Nitiéma P, Houston JB, Van Horn RL. Assessing community resilience: an application of the expanded CART survey instrument with affiliated volunteer responders. Am Behav Sci. 2015:59(2):181-99.

31. World Health Organization. Process of translation and adaptation of instruments. Geneva, Switzerland: World Health Organization. 2005. http://www.who.int/substanceabuse/research_tools/translation/en/. Accessed 30 April 2021.

32. Joseph S, Andrews B, Williams R, Yule W. Crisis support and psychiatric symptomatology in adult survivors of the Jupiter cruise ship disaster. $\mathrm{Br} J$ Clin Psychol. 1992;31(Pt 1):63-73.

33. Korean Ministry of Public Administration and Security. National Action Guidelines for Earthquake https://www.safekorea.go.kr/idsiSFK/neo/sfk/ cs/contents/prevent/prevent09.html?menuSeq=126. 2020. Accessed 20 July 2019.

34. Yesavage JA, Brink TL, Rose TL, Lum O, Huang V, Adey M, et al. Development and validation of a geriatric depression screening scale: a preliminary report. J Psychiatric Res. 1982;17(1):37-49.
35. Kee BS. A Preliminary study for the standardization of Geriatric Depression Scale Short Form-Korea Version. J Korean Neuropsychiatr Assoc. 1996:35(2):298-307.

36. Eun HJ, Kwon TW, Lee SM, Kim TH, Choi MR, Cho SJ. A study on reliability and validity of the Korean version of impact of event scale-revised. J Korean Neuropsychiatric Assoc. 2005;44(3):303-10.

37. Weiss DS, Marmar CR. The impact of event scale revised. In: Wilson JP, Keane TM, editors. Assessing psychological trauma and PTSD: A practitioner's handbook. New York, NY: Guilford Press; 1997. p. 399-411.

38. American Psychiatric Association. Diagnostic and statistical manual of mental of mental disorders (5th ed). Washington, DC: American Psychiatric Association; 2013.

39. Won CW, Yang KY, Rho YG, Kim SY, Lee EJ, Yoon JL, et al. The development of Korean activities of daily living (K-ADL) and Korean instrumental activities of daily living (K-IADL) scale. J Korean Geriatric Soc. 2002;6(2):107-20.

40. Doornik JA, Hansen $\mathrm{H}$. An omnibus test for univariate and multivariate normality. Oxf Bull Econ Stat. 2008;70:927-39.

41. Lei PW, Wu Q. Introduction to structural equation modeling: issues and practical considerations. Educ Meas. 2007;26(3):33-43.

42. Khachadourian V, Armenian HK, Demirchyan A, Goenjian A. Loss and psychosocial factors as determinants of quality of life in a cohort of earthquake survivors. Health Qual Life Outcomes. 2015;13:13.

43. Greiner C, Ono K, Otoguro C, Chiba K, Ota N. Intervention for the maintenance and improvement of physical function and quality of life among elderly disaster victims of the Great East Japan Earthquake and Tsunami. ANR. 2016;31:154-9.

44. Mazza M, Pacitti F, Pino MC, Peretti S, Mazzarelli E. Investigation on quality of life and psychological well-being of citizens of L'Aquila after earthquake on April 6, 2009. Riv Psichiatr. 2014;49(3):145-51.

45. lacoviello BM, Charney DS. Psychosocial facets of resilience: implications for preventing posttrauma psychopathology, treating trauma survivors, and enhancing community resilience. Eur J Psychotraumatol. 2014;5.

46. Cohen S, Wills TA. Stress, social support, and the buffering hypothesis. Psychol Bull. 1985;98(2):310

47. Lee KY, Lee YJ, Kim KM. Factor influencing the life satisfaction of Gyeongju citizen who experienced earthquake - Focused on disaster experience and awareness. Korean J Soc Welfare Res. 2017:54:83-110.

48. Tsai KY, Chou P, Chou FH, Su TT, Lin SC, Lu MK, et al. Three-year follow-up study of the relationship between posttraumatic stress symptoms and quality of life among earthquake survivors in Yu-Chi. Taiwan J Psychiatric Res. 2007;41(1-2):90-6.

49. Wen J, Shi YK, Li YP, Yuan P, Wang F. Quality of life, physical diseases, and psychological impairment among survivors 3 years after Wenchuan earthquake: a population based survey. PLoS One. 2012;7(8):e43081.

50. Wu HC, Chou P, Chou FH, Su CY, Tsai KY, Ou-Yang WC, et al. Survey of quality of life and related risk factors for a Taiwanese village population 3 years post-earthquake. Aust N Z J Psychiatry. 2006:40(4):355-61.

51. Zhao C, Wu Z, Xu J. The association between post-traumatic stress disorder symptoms and the quality of life among Wenchuan earthquake survivors: the role of social support as a moderator. Qual Life Res. 2013;22(4):733-43.

\section{Publisher's Note}

Springer Nature remains neutral with regard to jurisdictional claims in published maps and institutional affiliations. 